\title{
Case Report: Sinus of Valsalva Aneurysm, A Delayed Sequelae of Aortic Valve Endocarditis.
}

\author{
Basmah AlTinawi ${ }^{1}$, Salim Aziz ${ }^{2}$, Jenna Aziz ${ }^{3}$, and Junewai Reoma ${ }^{4}$ \\ ${ }^{1}$ Alfaisal University \\ ${ }^{2}$ Howard University Hospital \\ ${ }^{3}$ Affiliation not available \\ ${ }^{4}$ Munson Healthcare Inc
}

October 24, 2020

\begin{abstract}
Sinus of Valsalva aneurysms are unusual complications of endocarditis that can be fatal if not detected and treated. As the incidence of endocarditis continues to increase, and in patients not subjected to early surgery, our case suggests long term follow up should include imaging (echocardiography and computerized axial tomography), especially in patients with ongoing and unusual symptoms, despite negative blood cultures. This can also aid in planning of the surgical approach and treatment.
\end{abstract}

\section{Hosted file}

25_PSV__2020.pdf available at https://authorea.com/users/369833/articles/488652-case-reportsinus-of-valsalva-aneurysm-a-delayed-sequelae-of-aortic-valve-endocarditis 